\title{
TIME-SHARING OF A VISUAL IN-VEHICLE TASK WHILE DRIVING: THE EFFECTS OF FOUR KEY CONSTRUCTS
}

\author{
Omer Tsimhoni and Paul Green \\ University of Michigan \\ Transportation Research Institute \\ Ann Arbor, Michigan, USA \\ E-mail: omert@umich.edu
}

\begin{abstract}
Summary: What affects time-sharing of a visual in-vehicle task while driving? Four key constructs are considered: (1) time pressure to complete the in-vehicle task, (2) interference of concurrent driving, (3) postponed processing while looking away from the display, and (4) the cost of task partitioning (due to forgetting and the need to reacquire last point of gaze). To examine these effects, 24 drivers were instructed to plan routes to destinations on an electronic map while driving a simulator at three levels of visual demand of the concurrent driving task, and then while parked. To force task partitioning while parked, the map was intermittently occluded. There were six combinations of viewing and occlusion time.
\end{abstract}

Total task time increased significantly from $11.0 \mathrm{~s}$ while parked to $19.5 \mathrm{~s}$ on a sharp curve. Total glance time at the display, however, remained unchanged in all 4 levels of visual demand $(12.0 \pm 0.6 \mathrm{~s})$. Thus, the time pressure imposed by driving resulted in shorter glances at the display, but subjects maintained constant total glance time. Interference from concurrent driving was not significant enough to negate this effect. With task occlusion of $1 \mathrm{~s}$, when viewing time decreased from 2 to $1 \mathrm{~s}$, total task time increased from 15.9 to $19.7 \mathrm{~s}$. Total glance time, however, remained unchanged $(10.4 \pm 0.4 \mathrm{~s})$ in all 6 timing combinations. Thus, the costs of task partitioning and the benefits of postponed processing were either small or cancelled each other in this task. The task occlusion method, as described in this paper, provides a framework for understanding the effects of in-vehicle tasks on driving.

\section{INTRODUCTION}

As in-vehicle telematics devices become common, the problem of driver distraction associated with them becomes a greater concern. Prior research has shown that in-vehicle tasks with long eyes-off-the-road time degrade driving performance. (See Green, 1998, for a review.) Safe driving requires drivers to look at the road, and if they are looking elsewhere to perform an invehicle task, the risk of a crash increases. However, how characteristics of in-vehicle tasks affect eyes-off-the-road time (and the time-sharing behavior) has yet to be determined.

The time-sharing of visual in-vehicle tasks while driving is affected by at least four key constructs (Table 1). The effects of the first two can be tested by comparing task performance while parked and while driving at increasing levels of visual demand. The effects of the latter 
two can be tested using the task occlusion method, in which the in-vehicle display is intermittently occluded at fixed intervals, thus controlling the duration of glances. (See Tsimhoni, 2003 for a review.)

Table 1. Four constructs that may affect time-sharing of a visual in-vehicle task while driving

\begin{tabular}{lll}
\hline Construct & Comment & Effect on Time Sharing \\
\hline $\begin{array}{l}\text { 1. Time pressure to } \\
\text { look at the road }\end{array}$ & $\begin{array}{l}\text { A sense of immediacy to look back at the road } \\
\text { induces efficiency in performing the task. }\end{array}$ & $\begin{array}{l}\text { Shorter (more efficient) } \\
\text { glances at the display }\end{array}$ \\
$\begin{array}{l}\text { 2. Interference of } \\
\text { concurrent driving }\end{array}$ & $\begin{array}{l}\text { Cognitive demands of concurrent driving may } \\
\text { distract the driver while looking at the } \\
\text { display, thus degrading task performance. }\end{array}$ & $\begin{array}{l}\text { Longer total glance } \\
\text { time }\end{array}$ \\
$\begin{array}{l}\text { 3. Postponed } \\
\text { processing } \\
\text { Thd planning }\end{array}$ & $\begin{array}{l}\text { looking away from the display and plan ahead } \\
\text { for the next glance. }\end{array}$ & $\begin{array}{l}\text { Shorter total glance } \\
\text { time }\end{array}$ \\
$\begin{array}{l}\text { 4. The cost of task } \\
\text { partitioning }\end{array}$ & $\begin{array}{l}\text { If a task is stopped before completion, parts of } \\
\text { it might need to be repeated due to forgetting } \\
\text { or changes in the displayed information. }\end{array}$ & $\begin{array}{l}\text { Longer glances at the } \\
\text { display }\end{array}$ \\
\hline
\end{tabular}

To understand the effects of these characteristics, the following questions were examined:

1. In the task-occlusion method, how do the glance duration and the duration of occlusion affect timing characteristics of a visual in-vehicle task?

2. How can the results of the task occlusion method explain task partitioning while driving?

\section{METHOD}

Twenty-four licensed drivers participated in this experiment, 12 younger (ages 20 to 28) and 12 older (ages 65 to 71). Within each age bracket there were 6 men and 6 women.

In the first part of the experiment, subjects performed an in-vehicle task with 4 levels of visual demand -- parked, straight road, moderate curve $[R=388 \mathrm{~m}]$, and sharp curve $[\mathrm{R}=194 \mathrm{~m}]$ ). Prior research (Tsimhoni and Green, in press) has shown the visual demand on these curves to increase linearly. In part two, the in-vehicle task was performed while parked, with the display intermittently occluded (three map viewing intervals -- 1, 1.5, and $2 \mathrm{~s}$, combined with two occlusion intervals -- 1 and $3 \mathrm{~s}$ ). Half of the maps rotated at $2 \mathrm{deg} / \mathrm{s}$, which added an immediacy aspect and made the task more difficult.

The experiment was conducted in the "legacy" UMTRI Driver Interface Research Simulator, a fixed-based driving simulator (Olson and Green, 1997). The projection screen, offering a horizontal field of view of 33 degrees and a vertical field of view of 23 degrees, was $6 \mathrm{~m}$ in front of the driver, effectively at optical infinity. The single lane road was $3.6 \mathrm{~m}$ wide. All driving occurred with the cruise control set at $72.5 \mathrm{~km} / \mathrm{hr}(45 \mathrm{mi} / \mathrm{hr})$.

A simulated navigation map was displayed on an LCD monitor in the center console of the vehicle, $23 \pm 2$ degrees below the horizontal line of sight and $30 \pm 2$ degrees to the right of the center at a distance of about $80 \mathrm{~cm}$ (Figure 1). Maps (11.2 cm horizontal by $8.4 \mathrm{~cm}$ vertical) were displayed in the center of the display. The maps were all based on a common template 
(e.g., Figure 2) but differed from one another in the relative orientation of streets, the selection of street names, and the position of the target.

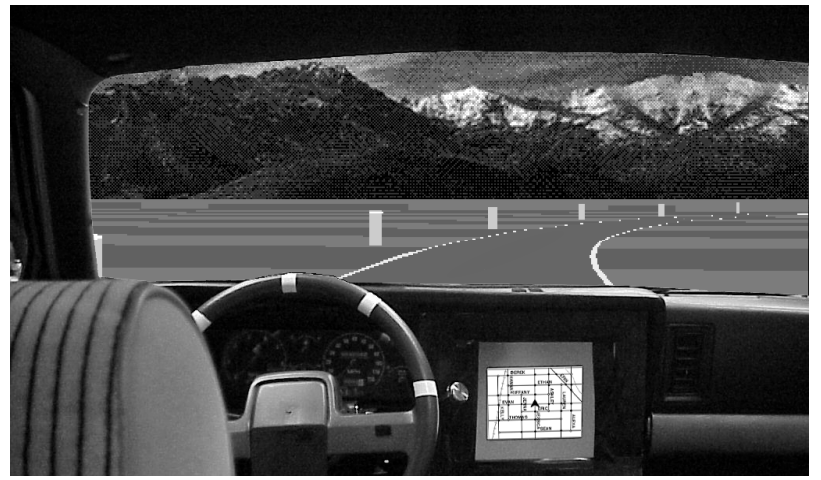

Figure 1. Driver's view

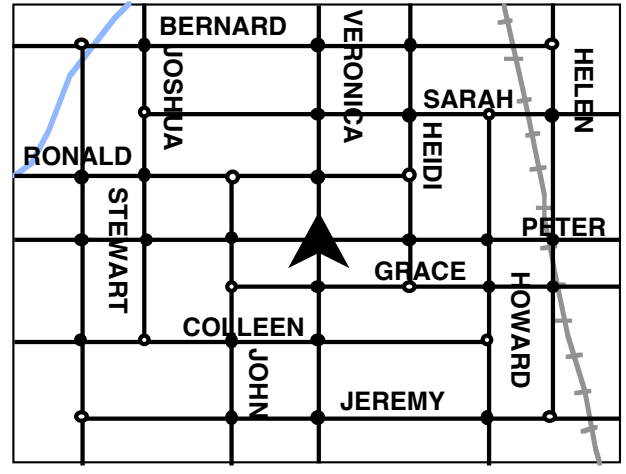

Figure 2. Sample map

Subjects were instructed to plan a route, based on predetermined rules, from the center of the map to a T-intersection specified by a street name. After hearing the street name they pressed a finger-switch to view the map. They then found where the street dead-ended and planned a route to that intersection while counting the cross intersections. Upon completion, they pressed the finger-switch again and called out the number of intersections along the route. (Using Figure 2 as an example: 'Bernard' dead-ends into 'Helen'. The planned route goes from the center up to 'Bernard' and then right to 'Helen'. The number of intersections including the target is five.)

The occlusion procedure, performed while parked, simulated in-vehicle task performance with intermittent glances away from the display. Forced occlusion, in which the subject had no control on timing, was used. Subjects were instructed to look at the road during the occlusion interval so that head movements and accommodation would resemble task performance while driving. A tone prior to the end of the occlusion interval cued them to look back at the display.

RESULTS For additional measures and analysis see Tsimhoni (2003).

\section{Task Performance while Driving}

Total glance time. Neither road curvature nor map rotation had a significant effect on total glance time while driving (Figure 3). When the map was static, total glance time remained unchanged at $12.0 \mathrm{~s}$, a slight increase from $11.0 \mathrm{~s}$ when parked. When the map rotated, greater variability was noted but differences were not statistically significant.

Total task time. The main effect of road curvature was significant ( $p<0.001$, Figure 4$)$. Total task time increased from $11.0 \mathrm{~s}$ while parked to $15.5 \mathrm{~s}$ on a straight road to 16.5 and $19.3 \mathrm{~s}$ on a moderate and sharp curve, respectively.

Single glance duration. The duration of glances to the display decreased with road curvature and was higher when the map rotated ( $p<0.0001$ and, $p<0.05$, respectively) (Figure 5). This serves as an indication that subjects changed their time-sharing strategies. Namely, they made shorter glances when driving was more demanding and made longer glances when the map rotated and the cost of looking away from the task was higher. 


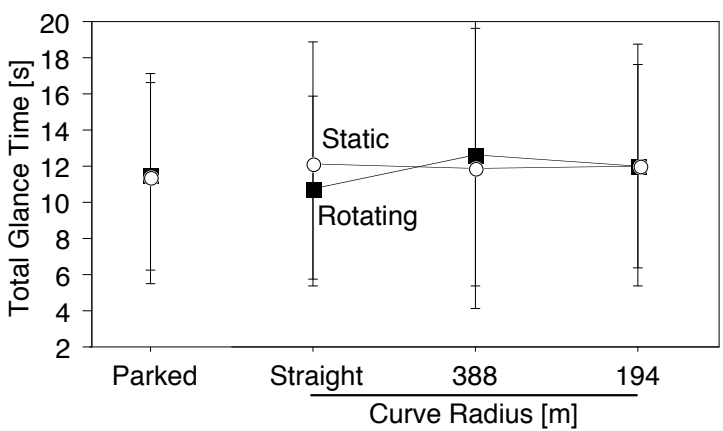

Figure 3. The effect of road curvature and map rotation on total glance time while driving

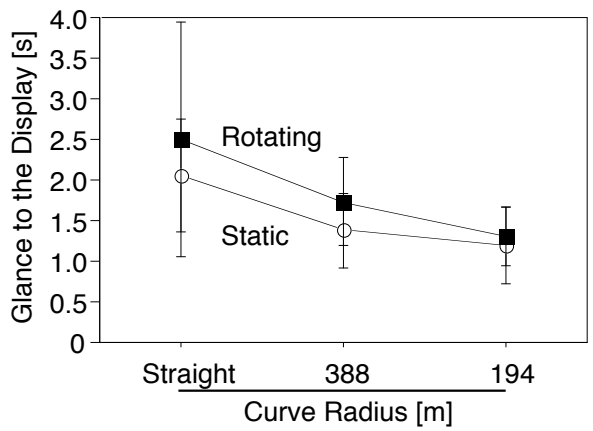

Figure 5. The effect of road curvature and map rotation on glances to the display

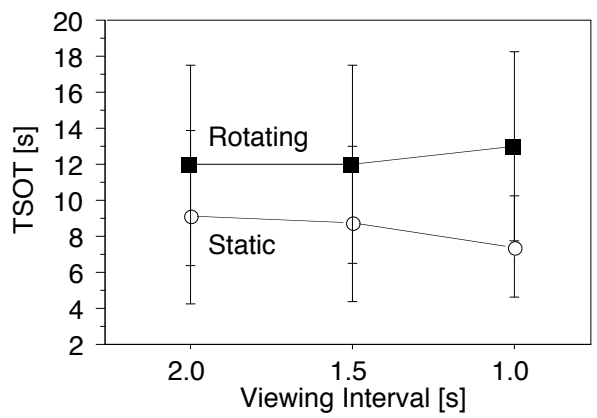

Figure 7. The effect of viewing interval and map rotation on TSOT

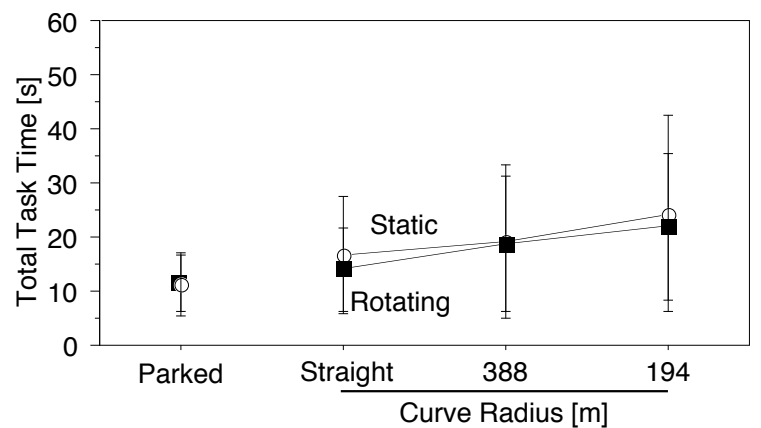

Figure 4. The effect of road curvature and map rotation on total task time while driving

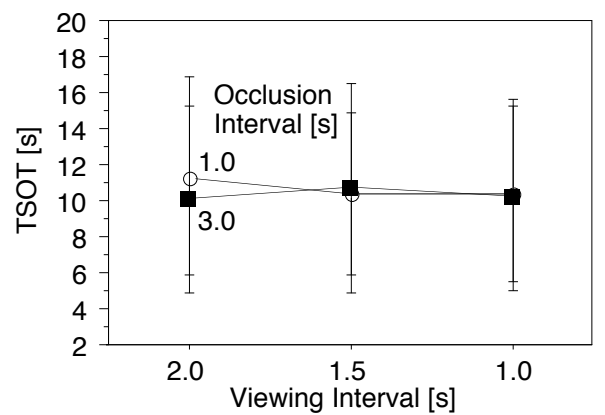

Figure 6. The effect of viewing interval and occlusion interval on TSOT

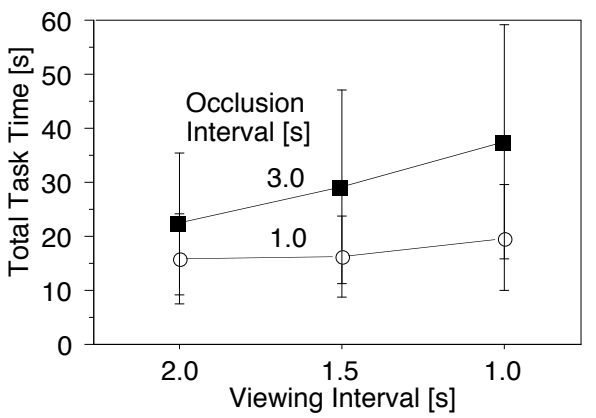

Figure 8. The effect of viewing and occlusion intervals on total task time

\section{Task Performance during Task Occlusion}

Total shutter open time (TSOT). Neither viewing time, nor occlusion time $(p<0.10)$, had a significant effect on total shutter open time (analogous to total glance time) (Figure 6).

TSOT of rotating maps (12.3 s) was higher than static maps $(8.4 \mathrm{~s}, p<0.001)$ (Figure 7). When viewing time decreased from 1.5 to $1.0 \mathrm{~s}$, TSOT of static maps decreased from 8.7 to $7.4 \mathrm{~s}$, most likely due to time pressure. Under the same conditions, TSOT of rotating maps increased from 12.0 to $13.0 \mathrm{~s}(p<0.0001)$, most likely due to the cost of partitioning.

Total task time. The main effects of viewing time, occlusion time, and the interaction between them on total task time were all statistically significant $(p<0.0001$, Figure 8$)$. When occlusion time was $3 \mathrm{~s}$ per interval and the viewing interval decreased from 2 to $1 \mathrm{~s}$, total task time 
increased from 22.4 to $37.5 \mathrm{~s}(+67 \%)$. Given that TSOT was constant, these increases were expected, as they merely reflect the added occlusion time.

\section{DISCUSSION}

Time pressure. Time pressure (caused by the need to look at the road more frequently when driving was more demanding) forced subjects to partition the task into smaller "chunks", but total glance time while driving remained unchanged. TSOT of static maps, however, decreased with viewing time, implying greater efficiency due to time pressure.

Interference of concurrent driving. Overall, total glance time did not increase with increasing levels of driving visual demand. Total glance time while driving was substantially higher than TSOT of static maps, demonstrating time cost due to interference.

Postponed processing. Postponed processing and planning ahead while looking away from the display should reduce total glance time. Accordingly, in the task occlusion part of the experiment, there was a slight decrease in TSOT from $11 \mathrm{~s}$ at baseline to $10.2 \mathrm{~s}$ when subjects were required to wait longer between glances ( $3 \mathrm{~s}$ occlusion). In practice, however, task performance while driving was not improved by this effect because glances at the road were always short (on the order of $1 \mathrm{~s}$ ).

Cost of task partitioning. Total glance time did not increase as the task was partitioned into smaller "chunks". This remained true even when the map rotated and thereby increased the cost of looking away from the display. This lack of apparent cost of task partitioning is possibly due to negation by other factors.

In summary, the results show that total eyes-off-road-time when performing a visual in-vehicle task is generally constant, though how that time is partitioned may change with test conditions. The effects of the four suggested constructs are evident in the data but they negate each other such that the resultant total glance times remain constant. Total task time, however, increases considerably as a result of shorter glances to the display and longer glances away from it.

\section{REFERENCES}

Green, P. (1998). Visual and Task Demands of Driver Information Systems (Technical Report UMTRI-98-16). Ann Arbor, MI: The University of Michigan Transportation Research Institute.

Olson, A. and Green, P. (1997). A Description of the UMTRI Driving Simulator Architecture and Alternatives (Technical report UMTRI-97-15). Ann Arbor, MI: The University of Michigan Transportation Research Institute.

Tsimhoni, O. (2003). Time-sharing of a visual in-vehicle task while driving: findings from the task occlusion technique (UMTRI-2003-13). Ann Arbor, MI: University of Michigan Transportation Research Institute.

Tsimhoni, O., \& Green, P. (in press). Visual demand of driving curves determined by visual occlusion. In Gale, A. G., Brown, I. D., Haslegrave, C. M., \& Taylor, S. P., (Eds.), Vision in Vehicles VIII. Amsterdam: Elsevier Science Publishers. 